\title{
XLIX. On the laws of chemical change.-Part I
}

\author{
John J. Hood Esq.
}

To cite this article: John J. Hood Esq. (1878) XLIX. On the laws of chemical change.-Part I, Philosophical Magazine Series 5, 6:38, 371-383, DOI: 10.1080/14786447808639527

To link to this article: http://dx.doi.org/10.1080/14786447808639527

曲 Published online: 13 May 2009.

Submit your article to this journal $\pi$

LII Article views: 4

Q View related articles $₫$

4 Citing articles: 11 View citing articles ๘ 
had to this circumstance, formula (E) obtains a higher numerical value than (F). From this it follows that the vertical component of the induction-force at the astronomic pole is less than at the point for which formula (E) holds good. If in formula (C) we make $l=90+34$, we obtain the sought force for a point $t^{\prime}$ situated at $56^{\circ}$ latitude counted from $d$. Formula (C) is in this way transformed into the following:-

$$
\begin{aligned}
& \frac{k \mathrm{M}\left(r \sin 34^{\circ}+\rho \sin 17^{\circ}\right) \rho \sin 51^{\circ}}{\left(r^{2}+\rho^{2}-2 r \rho \cos 51^{\circ}\right)^{\frac{3}{2}}} \\
& \quad+\frac{k \mathrm{M}\left(r \sin 34^{\circ}-\rho \sin 17^{\circ}\right) \rho \sin 51^{\circ}}{\left(r^{2}+\rho^{2}+2 r \rho \cos 51^{\circ}\right)^{\frac{3}{2}}} . .
\end{aligned}
$$

Formula (G) having a higher numerical value than $(E)$, the point at which the vertical component of the induction-force will be the same as at the point $t$ must be at a higher latitude than $t^{\prime}$. From this it follows that the aforesaid annular zone will cut the plane in question at a point $t^{\prime \prime}$ situated between the astronomic pole and $t^{\prime}$. Thus the zone presenting the greatest frequency of auroræ boreales must be at a higher latitude in Europe and Asia than in North America.

[To be continued.]

XLIX. On the Laws of Chemical Change--Part I. By JoHN J. HoOD, Esq.*

WHILE studying chemistry under Prof. Mills, I was much struck by the want of knowledge concerning the laws regulating the amount of change which chemically active bodies undergo in a given time, and in what manner the rate of change is influenced by heat, electricity, \&c. Many cases of change have been investigated and represented graphically; but, as far as I am aware, no theory has been given confirmed by experiment whereby, the temperature and amount of active bodies undergoing change being known, the amount of remaining energy at any time can be calculated. The nearest approach to such a theory was given by Messrs. Harcourt and Esson in the 'Phil. Trans.' for 1867 , where they showed that for the case of hydric peroxide reacting on hydric iodide,

$$
\mathrm{H}_{2} \mathrm{O}_{2}+2 \mathrm{HI}=2 \mathrm{H}_{2} \mathrm{O}+\mathrm{I}_{2} \text {, }
$$

the amount of change was proportional to the amount of acting substance, considering hydric peroxide as the active body.

* Communicated by the Author.

$2 \mathrm{~B} 2$ 
A thorough investigation on this point might lead to many interesting facts in science, and a clearer insight might be gained into molocular action.

For instance, by a comparison of the rates of change at different temperatures, all other conditions being the same, the necessary data could be obtained to deduce the law of temperature, and so find the point at which no action could take place; or, again, if analogous compounds, such as the sulphates, nitrates, chlorides, \&c., have an accelerating or retarding effect on the change, their "equivalence" might be determined or compared-that is to say, whether $\mathrm{K}_{2} \mathrm{SO}_{4}$, or 174 parts by weight of potassic sulphate, can perform the same amount of work as $\mathrm{Na}_{2} \mathrm{SO}_{4}$, or 142 parts of sodic sulphate.

The cases of chemical change selected for investigation would require to be under complete control, to allow of the determination of the amount of change up to any period of time, as it might so happen that the intervals of time between two observations would require to be equal in order to caleulate the necessary constants required by theory.

The methods of determining the remaining energy should be accurate and speedy.

When two bodies $\mathrm{A}$ and $\mathrm{B}$ undergo change and produce a third, C, which does not take an active part in the change, it will doubtless, by its mere presence, if not removed from the sphere of action, either accelerate or more probably retard the change taking place; and if this effect be great, supposing $\mathrm{C}$ not capable of being removed immediately it is formed, a mathematical statement of the change would not be possible, as the influence of $\mathrm{C}$ could not be determined. If, however, the rate of change is so little influenced by the presence of $C$ that it may be neglected, a theory of the action can easily be formed as a guide to the experimentalist.

The experiments detailed in this paper were made merely to see how far the following theory of chemical energy is correct, neglecting all retarding or accelerating effects of the compounds produced during the action. By an inspection of the results, it will be evident that this influence cannot be very large.

Suppose two bodies in solution which are capable of reacting on each other to form new inactive compounds, and the action taking place be expressed by an equation in terms of the time and the amounts of remaining active bodies at that time, on the hypothesis that the amount of change in an indefinitely small space of time is proportional to the product of the remaining active bodies at that time. Let $A$ and $B$ be 
the initial values of the bodies, $\alpha$ and $\beta$ the amounts of $A$ and $B$ that have already undergone change up to time $t$, and let $\delta \alpha$ be the amount of $A$ acted on in time $\delta t$; then, by the above hypothesis,

$$
\delta \alpha=\kappa(\mathrm{A}-\alpha)(\mathrm{B}-\beta) \delta t . \quad . \quad . \quad .
$$

Suppose, further, that the amounts of $A$ and $B$ are chemically equivalent (that is to say, they are just sufficient to render each other inactive), then the ratio

$$
\frac{\mathrm{A}}{\overline{\mathrm{B}}}=\frac{\alpha}{\bar{\beta}} ;
$$

call this $\frac{1}{\nu}$, and equation (1) becomes

$$
\delta \alpha=\kappa \nu(\mathrm{A}-\alpha)^{2} \delta t . \quad \text {. . . . . . }
$$

Replacing $\mathrm{A}-\alpha$ by $y$, the amount of $\mathrm{A}$ that remains unacted on at the time $t$,

$$
\frac{d y}{d t}=-\kappa \nu y^{2}, \quad . \quad . \quad . \quad . \quad . \quad . \quad . \quad .
$$

which, on integrating, gives

$$
\frac{1}{y}=(c+\kappa \nu t),
$$

or, writing it in the more convenient form,

$$
b=y(a+t), \quad \text {. . . . . . }
$$

being the equation to an equilateral hyperbola with axis $t$ for asymptote.

The influence of temperature and the non-equivalence of $\mathrm{A}$ and $B$ I will consider further on, after I show how far experiment agrees with this theory.

Experiments.-In the first experiments made, not knowing how the rate of change was influenced by heat, I took every care to keep the temperature of the water-bath perfectly constant; but in spite of every attention, the fluctuations were about $\pm \cdot 1^{\circ} \mathrm{C}$. This, I afterwards found, could not introduce any considerable error. The flasks containing the experimental solutions were submerged in the bath, and were never removed during the experiment. The solutions were freely exposed to the air, as it was found, after repeated trials, that atmospheric oxygen had not any perceptible influence on them during the time the experiments lasted.

The active bodies used were (1) a solution of ferrous sulphate containing an indefinite amount of hydric sulphate, and (2) a solution of potassic chlorate, the strengths of which were accurately known. 


\section{Mr. J. J. Hood on the Laws of Chemical Change.}

For the determination of the iron, a dilute solution of potassic permanganate was employed, the absolute strength of which was never determined, as the experiments were wholly relative. For the experiments made to find the influence of temperature on the rate of change it was necessary to express the different solutions of permanganate in terms of one standard, this being equivalent to using the same solution for all the experiments.

For measuring the solutions, 10-cubic-centim. and 50cubic-centim. burettes were employed ; the errors of calibration were so small that they were in every case neglected.

Experiment 1.-There were taken 100 eubic centims. ferrous sulphate solution containing $\cdot 5772$ gram ferrous iron with an indefinite amount of hydric sulphate, 10 cubic centims. potassic chlorate containing $\cdot 2104 \mathrm{grm}$., and 200 cubic centims. water: total volume 310 cubic centims.

$.5772 \mathrm{grm}$. iron is equivalent to $2105 \mathrm{grm} . \mathrm{KClO}_{3}$, by the equation

$$
\mathrm{KClO}_{3}+6 \mathrm{FeO}=\mathrm{KCl}+3 \mathrm{Fe}_{2} \mathrm{O}_{3} \text {. }
$$

All the solutions were immersed in the water-bath until they had acquired the necessary temperature before mixing, the iron solution being first run into the water, then the potassic chlorate, and the whole well shaken.

After standing in the bath five minutes, 10 cubic centims. were withdrawn as rapidly as possible, run into a small flask containing about 20 cubic centims. of water, to partially stop the action going on by the dilution, and the remaining iron determined by means of the permanganate, the whole operation occupying less than one minute. The time was always noted just when the iron solution withdrawn had run out the pipette.

As an excess of permanganate had always to be added to see the tint, $\cdot 02$ cubie centim. was deducted from the reading of the burette for the coloration; but in many cases no such deduction was made. When the iron to be determined was small, 20 or 30 cubic centims. were withdrawn for titration. The following Table contains the results of this experiment: the numbers under "permanganate calculated" are calculated by theory from the observed times, and those under "time calculated " from the permanganate found-the permanganate fonnd, or $y$, being the number of cubic centims. required for 10 cubic centims. of the experimental solution. for

Taking the first two observations to calculate the constants

we get

$$
\begin{aligned}
& y(a+t)=b, \\
& a=133 \cdot 84, \quad b=1338 \cdot 4 .
\end{aligned}
$$


Temperature $16^{\circ} \mathrm{C}$.

\begin{tabular}{|c|c|c|c|}
\hline \multicolumn{2}{|c|}{$\begin{array}{l}\text { Permangarate, in cubie } \\
\text { centims. }\end{array}$} & \multicolumn{2}{|c|}{ Time, in minutes. } \\
\hline Found. & Calculated. & Found. & Calculated. \\
\hline $\begin{array}{l}10 \\
8 \cdot 70 \\
7 \cdot 67 \\
6 \cdot 80 \\
5 \cdot 57 \\
4 \cdot 87 \\
4 \cdot 43 \\
3 \cdot 82 \\
3 \cdot 50 \\
3 \cdot 26 \\
3 \cdot 01 \\
2 \cdot 84 \\
2 \cdot 49 \\
2 \cdot 06 \\
1 \cdot 80 \\
1 \cdot 77\end{array}$ & $\begin{array}{l}7 \cdot 69 \\
6 \cdot 79 \\
5 \cdot 58 \\
4 \cdot 84 \\
4 \cdot 40 \\
3 \cdot 81 \\
3 \cdot 50 \\
3 \cdot 24 \\
3 \cdot 02 \\
2 \cdot 81 \\
2 \cdot 47 \\
2 \cdot 04 \\
1 \cdot 75 \\
1 \cdot 73\end{array}$ & \begin{tabular}{l}
\multicolumn{1}{c}{0} \\
20 \\
40 \\
63 \\
106 \\
$142 \cdot 4$ \\
170 \\
217 \\
$248 \cdot 5$ \\
279 \\
$309 \cdot 5$ \\
342 \\
406 \\
$520 \cdot 5$ \\
628 \\
639
\end{tabular} & $\begin{array}{l}40 \cdot 7 \\
63 \\
106 \times 4 \\
141 \\
168 \cdot 3 \\
216 \cdot 5 \\
248 \cdot 6 \\
276 \cdot 7 \\
310 \cdot 8 \\
337 \cdot 4 \\
403 \cdot 7 \\
515 \cdot 9 \\
609 \cdot 7 \\
622 \cdot 3\end{array}$ \\
\hline
\end{tabular}

Experiment 2.-The solutions employed were 50 cubic centims. ferrous sulphate (equal to .9847 grm. Fe), 10 cubic centims. potassic chlorate containing $3593 \mathrm{grm}$. $\mathrm{KClO}_{3}$, and 400 cubic centims. water ; total volume 460 cubic centims. The following Table contains the results of this experiment. Taking the second and third observations for the constants $a$ and $b$, the equation is

$$
y(222 \cdot 8+t)=2512 \cdot 1 \text {. }
$$

Temperature $18^{\circ} \mathrm{C}$.

\begin{tabular}{|c|c|c|c|}
\hline \multicolumn{2}{|c|}{$\begin{array}{l}\text { Permanganate, in cubic } \\
\text { centims. }\end{array}$} & \multicolumn{2}{|c|}{ Time, in minutes. } \\
\hline Found. & Calculated. & Found, & Calculated. \\
\hline $11 \cdot 21$ & $11 \cdot 27$ & 0 & 1.3 \\
\hline $11 \cdot 10$ & ...... & 35 & \\
\hline $\mathbf{9 \cdot 8 2}$ & & 33 & \\
\hline $8 \cdot 48$ & 8.52 & 72 & $73 \cdot 3$ \\
\hline $7 \cdot 56$ & $7 \cdot 59$ & 108 & 109.5 \\
\hline 6.76 & 6.72 & 151 & $148 \cdot 8$ \\
\hline 6.54 & 6.54 & 161 & $161 \cdot 3$ \\
\hline $5 \cdot 96$ & $5 \cdot 95$ & $199 \cdot 3$ & 198.7 \\
\hline $5 \cdot 63$ & $5 \cdot 65$ & 229 & 223.4 \\
\hline $5 \cdot 32$ & $5 \cdot 30$ & 251 & $249 \cdot 4$ \\
\hline 4.98 & 4.96 & 283 & $281 \cdot 6$ \\
\hline $\begin{array}{l}4 \cdot 68 \\
4 \cdot 34\end{array}$ & $\begin{array}{l}4 \cdot 68 \\
4 \cdot 33\end{array}$ & $\begin{array}{l}315 \\
357\end{array}$ & $\begin{array}{l}314 \\
356\end{array}$ \\
\hline $4 \cdot 12$ & $4 \cdot 11$ & 388 & 386.9 \\
\hline 3.95 & $\mathbf{3 \cdot 9 2}$ & 418 & $413 \cdot 1$ \\
\hline $3 \cdot 76$ & 370 & $\$ 55$ & $445 \cdot 3$ \\
\hline 369 & $\mathbf{3} \cdot 67$ & 461 & 458 \\
\hline $3 \cdot 42$ & $3 \cdot 40$ & 515 & 511.7 \\
\hline $3 \cdot 22$ & $3 \cdot 21$. & 560 & $557 \cdot 4$ \\
\hline 3.03 & 2.99 & 617 & $606 \cdot 3$ \\
\hline $2 \cdot 94$ & 2.92 & 638 & 631.6 \\
\hline $2 \cdot 63$ & 261 & 739 & 732.4 \\
\hline $2 \cdot 34$ & $2 \cdot 30$ & 869 & 851 \\
\hline $2 \cdot 13$ & $2 \cdot 10$ & 972 & 957 \\
\hline
\end{tabular}


376 Mr. J. J. Hood on the Laws of Chemical Change.

Experiments 3 and 4.-Both these experiments were made at the same time and under similar conditions; each stood five minutes before an observation was made. The solution consisted of 25 cubic centims. ferrous sulphate (equal to -4923 grm. iron), 5 cabic centims. potassic chlorate, or $\cdot 1796$ grm., and 200 cubic centims. water.

Taking the second and third observations for the constants for No. 3,

and No. 4,

$$
\begin{aligned}
& y(103 \cdot 1+t)=967 \cdot 23, \\
& y(104 \cdot 5+t)=976 \cdot 1 .
\end{aligned}
$$

The results are tabulated below.

\begin{tabular}{|c|c|c|c|}
\hline \multicolumn{2}{|c|}{$\begin{array}{l}\text { Permanganate, in cubic } \\
\text { centims. }\end{array}$} & \multicolumn{2}{|c|}{ Time, in minutes. } \\
\hline Found. & Calculated. & Found. & Calculated. \\
\hline $\begin{array}{l}9 \cdot 34 \\
8 \cdot 60 \\
6 \cdot 77 \\
5 \cdot 60 \\
4 \cdot 70 \\
3 \cdot 92 \\
3 \cdot 39 \\
2 \cdot 73 \\
2 \cdot 34 \\
2 \cdot 04 \\
1 \cdot 69 \\
1 \cdot 53 \\
1 \cdot 28\end{array}$ & $\begin{array}{l}9 \cdot 38 \\
\ldots \ldots . \\
\ldots \ldots \ldots \\
5 \cdot 58 \\
4 \cdot 68 \\
3 \cdot 87 \\
3 \cdot 26 \\
2 \cdot 70 \\
2 \cdot 31 \\
2 \cdot 02 \\
1 \cdot 66 \\
1 \cdot 52 \\
1 \cdot 26\end{array}$ & $\begin{array}{c}0 \\
9 \cdot 4 \\
\mathbf{3 9} \cdot 8 \\
70 \\
\mathbf{1 0 3 \cdot 5} \\
146 \cdot 5 \\
193 \cdot 6 \\
254 \cdot 5 \\
316 \\
377 \\
\mathbf{4 7 9} \\
\mathbf{5 3 2} \\
\mathbf{6 6 1}\end{array}$ & $\begin{array}{l}69 \cdot 6 \\
102 \cdot 7 \\
143 \cdot 6 \\
190 \\
251 \cdot 2 \\
310 \cdot 2 \\
371 \\
469 \cdot 2 \\
529 \\
652 \cdot 2\end{array}$ \\
\hline
\end{tabular}

Temperature $20^{\circ} \mathrm{C}$. No. 3 .

\begin{tabular}{|c|c|c|c|}
\hline \multicolumn{2}{|c|}{$\begin{array}{l}\text { Permanganate, in cubic } \\
\text { centims. }\end{array}$} & \multicolumn{2}{|c|}{ Time, in minutes. } \\
\hline Found. & Calculated. & Found. & Calculated. \\
\hline $\begin{array}{l}9 \cdot 30 \\
8 \cdot 19 \\
6 \cdot 65 \\
5 \cdot 46 \\
4 \cdot 59 \\
3 \cdot 84 \\
3 \cdot 24 \\
2 \cdot 67 \\
2 \cdot 33 \\
2 \cdot 00 \\
1 \cdot 67 \\
1 \cdot 50 \\
1 \cdot 25\end{array}$ & $\begin{array}{l}9 \cdot 34 \\
\ldots \ldots . . \\
\ldots \ldots . \\
5 \cdot 45 \\
4 \cdot 58 \\
3 \cdot 83 \\
3 \cdot 23 \\
2 \cdot 69 \\
2 \cdot 31 \\
1.97 \\
1 \cdot 66 \\
1 \cdot 51 \\
1 \cdot 26\end{array}$ & $\begin{array}{l}0 \\
14 \cdot 7 \\
42 \cdot 3 \\
74 \cdot 5 \\
108 \cdot 5 \\
150 \\
197 \cdot 5 \\
\mathbf{2 5 9} \\
\mathbf{3 1 8} \\
\mathbf{3 9 0} \\
\mathbf{4 8 3} \\
\mathbf{5 4 2} \\
668\end{array}$ & $\begin{array}{r}\cdot 4 \\
\ldots \ldots . . \\
\ldots \ldots . \cdot \\
74 \cdot 2 \\
108 \cdot 1 \\
149 \cdot 6 \\
196 \cdot 7 \\
261 \\
314 \cdot 4 \\
383 \cdot 5 \\
480 \\
546 \cdot 2 \\
676.3\end{array}$ \\
\hline
\end{tabular}

No. 4. 
As a criterion of the probability of the supposed law, I have calculated the areas enclosed between the curve $y(a+t)=b$, axis $y$, and asymptote $t$, with the limits for time of last observation and zero, on the supposition that the law holds good between the two observations selected to determine $a$ and $b$.

Thus

$$
\begin{aligned}
\text { area } & =\int_{0}^{\mathrm{T}} y d t \\
& =b \log _{\mathrm{e}}\left(1+\frac{\mathrm{T}}{a}\right)
\end{aligned}
$$

or

taking $\log _{\varepsilon} 10=2 \cdot 3026$.

$$
b \log _{\varepsilon} 10 \log _{10}\left(1+\frac{T}{a}\right)
$$

The areas were also calculated from the experimental numbers by the formula

$$
\text { area }=\Sigma\left(\frac{y_{n+1}+y_{n}}{2}\right)\left(t_{n+1}-t_{n}\right)
$$

which is approximately true, independently of any law. The results are given below with the percentage differences of

\begin{tabular}{|c|c|c|c|}
\hline & Theory. & Found. & $\begin{array}{l}\text { Percentage } \\
\text { difference. }\end{array}$ \\
\hline 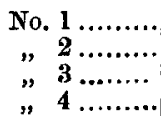 & $\begin{array}{l}2346 \cdot 8 \\
4219 \\
1937 \cdot 3 \\
1952 \cdot 6\end{array}$ & $\begin{array}{l}2362 \cdot 4 \\
4239 \cdot 9 \\
1962 \cdot 5 \\
1964 \cdot 7\end{array}$ & $\begin{array}{r}.66 \\
.50 \\
1.24 \\
.62\end{array}$ \\
\hline
\end{tabular}
"found" from theory. As the curve is convex to axis $t$, it is evident that the areas calculated by the latter formula should be slightly greater than theory.

The question now arises, What will be the form of the equation representing the change when there is an excess of either of the active bodies present? Taking equation (1),

$$
\frac{d \alpha}{d t}=\kappa(\mathrm{A}-\alpha)(\mathrm{B}-\beta)
$$

and supposing there is an excess of $B$ sufficient to act on $n$ times the amount of $A$ present, then, as before, $B=\nu n A$, and also $\beta=v \alpha$. Since the amount of $B$ rendered inactive is proportional to that of $A$ up to any time, the above equation becomes

$$
\frac{d \alpha}{d t}=\nu \kappa(\mathrm{A}-\alpha)(n \mathrm{~A}-\alpha) . \quad . \quad . \quad . \quad .
$$


Since $\mathrm{A}$ and $n \mathrm{~A}$ are the values of the active bodies before the action begins, they cannot be taken as the initial values when $t=0$, as the equation only applies when the change is actually going on, and the solutions require to stand a few minutes after mixing to allow the action to get into a normal state before the first observation can be made, when $t$ is to be taken as $=0$. Putting $y=\mathrm{A}-\alpha$, or amount remaining at time $t$, the equation becomes

$$
\frac{d y}{d t}=-\kappa \nu y((n-1) \mathrm{A}+y), . \quad . \quad . \quad . \quad .
$$

the solution of which is

$$
\frac{1}{(n-1) \mathrm{A}} \log _{e} \frac{y}{(n-1) \mathrm{A}+y}=\mathrm{C}-\kappa \nu t .
$$

Let $a$ be the value of $y$ when $t=0$,

$$
\mathrm{C}=\frac{1}{(n-1) \mathrm{A}} \log _{\epsilon} \frac{a}{(n-1) \mathrm{A}+a} ;
$$

and inserting this value, the final equation becomes

where

$$
-t=\mathrm{C}^{\prime} \log _{10}\left\{\left(\frac{y}{(n-1) \mathrm{A}+y}\right)\left(\frac{(n-1) \mathrm{A}+a}{a}\right)\right\},
$$

$$
\mathrm{C}^{\prime}=\frac{\log _{\mathrm{e}} 10}{\kappa \nu(n-1) \mathrm{A}}
$$

This equation is established on the same supposition as (4), and that the compounds formed during the action bave little influence on the change either as retarding or accelerating agents, as indeed the experiments indicate.

Experiments.-As yet I have not been able to try very extreme values for $n$; in the experiments made it only ranged from 5 to 5 ; above this latter value the action proceeded so rapidly that large errors occurred, rendering the results worthless : still I think the following experiments may be of interest as showing the truth of the formula.

The method of making the experiments was exactly the same as for those given in the first part of this paper.

Experiment $(\alpha)$.-The solutions employed were 25 cubic centims. ferrous sulphate (equal to 4923 grm. iron), 10 cubic centims. potassie chlorate containing 3593 grm., and 260 cubic centims. water-total volume 295 cubic centims,-this quantity of potassic chlorate being able to oxidize twice the amount of iron present, or $n=2$. The number of cubic centims. of permanganate required for 10 cubic centims. of this solution before the action commenced, or the value of $A$, was 
determined by making a solution of iron containing 4923 grm. Fe in 295 cubic centims. water and titrating 10 cubic centims. with the permanganate used in the experiment; its value was found to be $10 \cdot 36$ cubic centims., the values of $y$ being, as before, the number of cubic centims. of permanganate required for 10 cubic centims. of the experimental solution.

The first observation, at $t=0$, gave $y=9.45$ cubic centims.; and when $t=30 \cdot 5$ units, $y=7 \cdot 30$ cubic centims. Taking equation (8),

$$
-t=\mathrm{C}^{\prime} \log _{10}\left\{\left(\frac{y}{y+(n-1) \mathrm{A}}\right)\left(\frac{(n-1) \mathrm{A}+a}{a}\right)\right\}
$$

and inserting those values, using the second observation to find $\mathrm{C}^{\prime}$, we get

$$
-t=490 \cdot 2 \log _{10}\left(\frac{y}{y+10 \cdot 36}\right)\left(\frac{19 \cdot 81}{9 \cdot 45}\right) \text {. }
$$

The values of $t$ are calculated from this equation (in minutes), using the observed values of $y$, and are compared with those observed. The close agreement between theory and experiment is very striking.

\begin{tabular}{|c|c|c|}
\hline $\begin{array}{l}\text { Permanganate, in } \\
\text { cubic centims. }\end{array}$ & \multicolumn{2}{|c|}{ Time, in minutes. } \\
\hline Found. & Found. & Calculated. \\
\hline $\begin{array}{r}9 \cdot 45 \\
7 \cdot 30 \\
5 \cdot 98 \\
4 \cdot 74 \\
4 \cdot 06 \\
3 \cdot 30 \\
2 \cdot 63 \\
2 \cdot 30 \\
1 \cdot 98 \\
1 \cdot 58 \\
1 \cdot 11 \\
98\end{array}$ & $\begin{array}{c}\mathbf{0} \\
\mathbf{3 0 \cdot 5} \\
\mathbf{5 5} \\
\mathbf{8 9} \\
\mathbf{1 1 2 \cdot 2} \\
\mathbf{1 4 3 \cdot 2} \\
\mathbf{1 8 0 \cdot 5} \\
\mathbf{2 0 6 \cdot 8} \\
\mathbf{2 3 7 \cdot 5} \\
\mathbf{2 7 2} \\
\mathbf{3 3 6 \cdot 3} \\
\mathbf{3 6 0}\end{array}$ & $\begin{array}{r}56.4 \\
89.1 \\
112.6 \\
144.8 \\
182.5 \\
205.5 \\
286.5 \\
273 \\
334.4 \\
363.7\end{array}$ \\
\hline
\end{tabular}

Temperature $18^{\circ} \mathrm{C} . \quad n=2$.

Experiment $(\beta)$.-Every thing the same as before, except the ratio of the iron to the potassic chlorate, viz. $1: 3$, or $n=3$, and total volume 300 cubic centims. The value for $A$ was found to be $10 \cdot 18$ cubic centims.; and taking the first two observations for $a$ and $C^{\prime}$, we get

$$
-t=257 \cdot 4 \log _{10}\left\{\left(\frac{y}{y+20 \cdot 36}\right)\left(\frac{30 \cdot 11}{9 \cdot 75}\right)\right\} .
$$

The results are given below. 
Temperature $18^{\circ} \mathrm{C} . \quad n=3$.

\begin{tabular}{|c|c|c|}
\hline $\begin{array}{c}\text { Permanganate, in } \\
\text { cubic centims. }\end{array}$ & \multicolumn{2}{|c|}{ Time in minutes. } \\
\hline Found. & Found. & Calculated. \\
\hline $9 \cdot 75$ & 0 & \\
$7 \cdot 20$ & 24 & \\
$5 \cdot 23$ & $50 \cdot 3$ & $51 \cdot 4$ \\
$3 \cdot 73$ & $81 \cdot 8$ & $82 \cdot 5$ \\
$2 \cdot 86$ & 106 & $108 \cdot 1$ \\
$2 \cdot 06$ & $139 \cdot 3$ & $140 \cdot 3$ \\
$1 \cdot 46$ & $172 \cdot 8$ & $172 \cdot 6$ \\
$1 \cdot 15$ & $199 \cdot 5$ & $201 \cdot 3$ \\
$\cdot 85$ & 231 & $233 \cdot 5$ \\
61 & 264 & $269 \cdot 4$ \\
\hline
\end{tabular}

Experiment $(\gamma)$.-The ratio of the potassic chlorate to the iron was as $4: 1$, or $n=4$; and $A$ was found by experiment to be 9.78 cubic centims. Using the first and third observation for $a$ and $\mathrm{C}^{\prime}$, we get

$$
-t=534 \cdot 1 \log _{10}\left\{\left(\frac{y}{y+29 \cdot 34}\right)\left(\frac{38 \cdot 9}{9 \cdot 56}\right)\right\} \text {. }
$$

Temperature $17^{\circ} \cdot 8$ C. $n=4$.

\begin{tabular}{|c|c|c|}
\hline $\begin{array}{l}\text { Permanganate in } \\
\text { cubic centims. }\end{array}$ & \multicolumn{2}{|c|}{ Time, in minutes. } \\
\hline Found. & Found. & Calculated. \\
\hline $\begin{array}{c}9 \cdot 56 \\
8 \cdot 36 \\
7 \cdot 26 \\
6 \cdot 38 \\
5 \cdot 56 \\
4 \cdot 86 \\
4 \cdot 32 \\
3.86 \\
3.07 \\
2 \cdot 68 \\
2 \cdot 22 \\
1.98 \\
1 \cdot 71 \\
1 \cdot 35 \\
1 \cdot 30 \\
1 \cdot 1 \\
\cdot 85\end{array}$ & $\begin{array}{c}0 \\
25 \cdot 7 \\
49 \cdot 7 \\
75 \cdot 1 \\
104 \\
\mathbf{3 2 8 \cdot 3} \\
152 \cdot 5 \\
175 \\
217 \cdot 5 \\
249 \\
293 \cdot 5 \\
317 \cdot 5 \\
346 \cdot 5 \\
402 \\
410 \cdot 5 \\
447 \cdot 5 \\
508\end{array}$ & $\begin{array}{c}23 \cdot 8 \\
74 \\
74 \cdot 8 \\
100 \cdot 5 \\
127 \\
150 \cdot 7 \\
173 \cdot 6 \\
221 \cdot 1 \\
249 \cdot 8 \\
290 \cdot 2 \\
315 \\
346 \cdot 9 \\
399 \cdot 1 \\
407 \cdot 4 \\
444 \cdot 7 \\
502 \cdot 6\end{array}$ \\
\hline
\end{tabular}

Experiment $(\delta)$.- In this case there was an excess of iron present, which alters the form of the equation on account of $n$ being less than unity, the ratio of iron to potassic chlorate being as $1: \cdot 8$, or $n=\cdot 8$; A was found to be $9 \cdot 40$ cubic centims. Taking the second and third observations for $\mathrm{C}$, 
Mr. J. J. Hood on the Laws of Chemical Change. $\quad 381$ and not the first for $a$, on account of its being faulty, we get

$$
t-25 \cdot 6=2275 \cdot 7 \log _{10}\left\{\left(\frac{y}{y-1 \cdot 88}\right)\left(\frac{6 \cdot 5}{8 \cdot 38}\right)\right\} \text {. }
$$

Temperature $17^{\circ} \cdot 8$ C. $n=\cdot 8$.

\begin{tabular}{|c|c|c|}
\hline $\begin{array}{c}\text { Permanganate, in } \\
\text { cubic centims. }\end{array}$ & \multicolumn{2}{|c|}{ Time, in minutes. } \\
\hline Found. & Found. & Calculated. \\
\hline $9 \cdot 17$ & 0 & $1 \cdot 3$ \\
$8 \cdot 38$ & $25 \cdot 6$ & \\
$7 \cdot 77$ & $\mathbf{4 8 \cdot 3}$ & \\
$7 \cdot 20$ & $74 \cdot 6$ & 73.5 \\
$6 \cdot 68$ & $102 \cdot 8$ & $101 \cdot 1$ \\
6.30 & $126 \cdot 8$ & $124 \cdot 8$ \\
5.96 & 151 & $149 \cdot 1$ \\
$5 \cdot 70$ & 173 & $170 \cdot 1$ \\
$5 \cdot 26$ & $216 \cdot 5$ & $211 \cdot 6$ \\
$4 \cdot 95$ & $248 \cdot 5$ & $246 \cdot 8$ \\
$4 \cdot 64$ & 292 & 288 \\
$4 \cdot 48$ & $315 \cdot 5$ & $312 \cdot 2$ \\
$4 \cdot 26$ & 345 & $349 \cdot 2$ \\
$3 \cdot 98$ & $401 \cdot 5$ & $406 \cdot 4$ \\
$3 \cdot 88$ & 438 & $429 \cdot 5$ \\
3.57 & 508 & $513 \cdot 6$ \\
\hline
\end{tabular}

The criterion of areas applied to those experiments gives very close results. The approximately true areas are given by the formula

$$
\Sigma\left(\frac{y_{n+1}+y_{n}}{2}\right)\left(t_{n+1}-t_{n}\right) ;
$$

and the real areas are found by assuming the curve to be

$$
t=\mathrm{C}^{\prime} \log _{10} \frac{a y}{b+y}
$$

which gives for the area between the curve and axes, taking the limits for $y$ of first and last experiment,

$$
\text { area }=b \mathrm{C}^{\prime} \log _{10}\left(\frac{b+y}{b+\mathrm{Y}}\right)
$$

\begin{tabular}{|c|c|c|c|}
\hline & Theory. & Found. & $\begin{array}{l}\text { Percentage } \\
\text { difference. }\end{array}$ \\
\hline $\begin{array}{l}\alpha \ldots \ldots \ldots . . \\
\beta \\
\beta \\
\gamma \ldots \ldots \ldots \ldots . . .\end{array}$ & $\begin{array}{c}1230 \cdot 4 \\
823 \cdot 4 \\
1725 \\
2716\end{array}$ & $\begin{array}{l}1229 \cdot 6 \\
819 \\
1744 \\
2716 \cdot 2\end{array}$ & $\begin{array}{r}.53 \\
1 \mathrm{JI}\end{array}$ \\
\hline
\end{tabular}

using the constants found by experiment.

Areas. 
In all the experiments given in this paper there is one special point to which I wish to draw attention; and that is that only two observations are taken to find the necessary constants ; if these had been calculated for each pair of observations and the means taken, better agreement with theory would doubtless have been obtained; but such a procedure is apt to throw doubts on a theory, as to which, if it were true, one observation should be as good as another for determining the constants, unless large errors were suspected.

Before selecting those observations which were to be taken for the constants, the first few were laid off graphically, and those which seemed to be the most regular were chosen.

Influence of Temperature.-Chemical decompositions are all more or less influenced by heat, the effect being an acceleration of the rate of change; but it is very probable there is a point at or below which temperature no change can take place, as in the many cases where an acid has not action on a body at the ordinary temperature, while on heating to about $100^{\circ} \mathrm{C}$. change goes on briskly.

The relation of the rate of change to the temperature and the point of zero action are possible to be discovered by the foregoing experiments in a simple manner.

It has been shown that the rate of change is expressed by the equation

$$
\frac{d y}{d t}=-\mu y^{2}
$$

and if it be proportional to an unknown function of the temperature $f(\theta), \theta$ being degrees Centigrade above the zeropoint, so that

$$
\frac{d y}{d t}=-\mu f(\theta) y^{2}
$$

integrating,

$$
\frac{1}{\mu f(\theta)}=y\left(\frac{\mathrm{C}}{\mu f(\theta)}+t\right)
$$

writing it in the usual form,

$$
b=y(a+t)
$$

$b$ and $a$ being determined experimentally. If for a second experiment under exactly the same conditions, but temperature differing by $n^{\circ} \mathrm{C}$., the equation is found to be

$$
b^{\prime}=y\left(a^{\prime}+t\right)
$$

we get at once the relation

$$
\frac{b}{b^{\prime}}=\frac{f(\theta+n)}{f(\theta)}
$$


but it does not follow that $\frac{a}{a^{\prime}}$ is also equal to this ratio, unless the value for $y$ when $t=0$ is the same in each case.

A number of experiments were made to determine $f(\theta)$; but as the temperatures ranged only from $18^{\circ}$ to $22^{\circ} \mathrm{C}$., and they are rather incomplete, I refrain from giving them fully; the results, however, seemed to indicate that $f(\theta)=\theta^{2}$, or that the rate of change varies as the square of the temperature from the zero-point ; and on this hypothesis the point of no action was found to range from $+2^{\circ} \mathrm{C}$. to $-2^{\circ} \mathrm{C}$., or about the temperature at which the solution would become ice.

In conclusion, I may state that the following experiments were made. An increase in the amount of $\mathrm{H}_{2} \mathrm{SO}_{4}$ accelerates the change, still obeying the law. Ferrous chloride, in presence of $\mathrm{HCl}$, is oxidized by $\mathrm{KClO}_{3}$, at $18^{\circ} \mathrm{C}$, approximately according to the law $y(a+t)=b$, the discrepancies in this case being caused by the difficulty of accurately determining the iron by permanganate in presence of free hydric chloride. Ferrous sulphate in hydric sulphate is only very slowly acted on by potassic nitrate in the cold, probably being too near the zero-point.

I hope soon to give the results of some experiments on the rates of change for the various chlorates, as potassic against sodic chlorate, and possibly get some relation between the dynamical equivalences of those salts.

Glasgow, August 1878.

L. Phenomena of Binaural Audition.-Part II. By Silvanus P. Thompson, D.Sc., B.A., Professor of Experimental Physics in University College, Bristol*.

1. T $N$ a paper read before Section $A$ of the British Associa1 tion last year (1877) on Binaural Auditiont, the author communicated the discovery of two phenomena: first, the existence of an interference in the perception of sound; secondly, an apparent localization of simple sounds at the back of the head when led to the two ears in such a manner that the vibrations reached the ears simultaneously in opposite phases. The present paper recapitulates the former experiments, and gives some further account of the phenomena and of new methods of experimentation.

2. The existence of an interference in the perception of

* Communicated by the Author.

$\dagger$ Rep. Brit. Assoc. Plymouth, 1877, p. 37; Phil. Mag. October 1877, p. 274. 